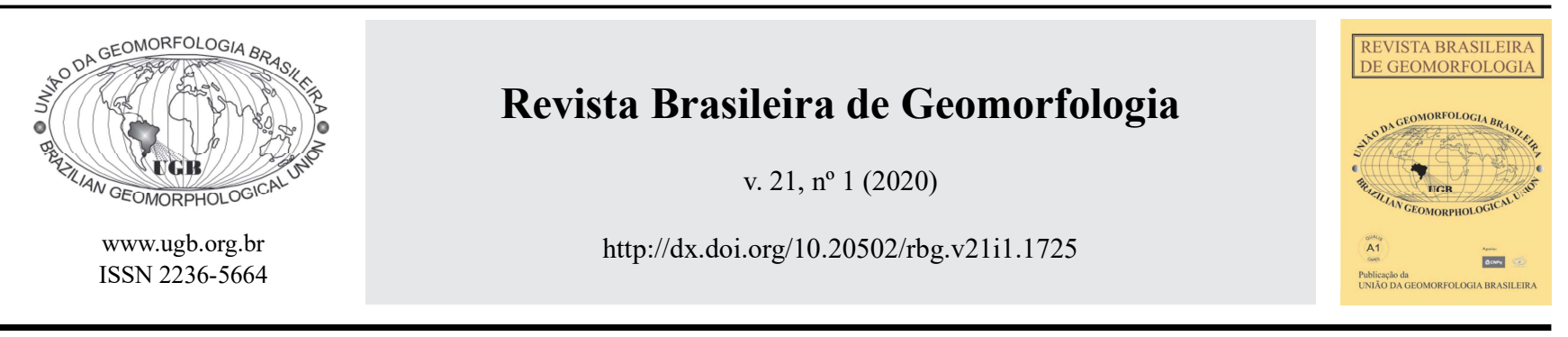

NOTA TÉCNICA

\title{
PERFIS DE PRAIA: DEVE O MÉTODO DAS BALIZAS DE EMERY SER ABANDONADO?
}

\section{BEACH PROFILES: SHOULD THE EMERY ROD METHOD BE DISCARDED?}

Dieter Muehe

Programa de Pós-Graduação em Oceanografia Ambiental, Universidade Federal do Espírito Santo Av. Fernando Ferrari, 514, Vitória, Espírito Santo. CEF: 29075-910. Brasil ORCID: 0000-0002-6061-4034 E-mail:dieter.muehe@gmail.com

Lucas Bermudes de Castro

Programa de Pós-Graduação em Oceanografia Ambiental, Universidade Federal do Espírito Santo Av. Fernando Ferrari, 514, Vitória, Espirito Santo. CEF: 29075-910. Brasil

ORCID: 0000-0002-1992-7813

E-mail: lucasbdec@gmail.com

Jacqueline Albino

Programa de Pós-Graduação em Oceanografia Ambiental, Universidade Federal do Espírito Santo Av. Fernando Ferrari, 514, Vitória, Espírito Santo. CEF: 29075-910. Brasil ORCID: 0000-0003-2890-9227

E-mail albino.jacqueline@gmail.com

Informações sobre o Artigo

Recebido (Received):

24/06/2019

Aceito (Accepted):

05/09/2019

\section{Palavras-chave:}

Praia; Perfil de Praia; Nivelamento Topográfico; Balizas de Emery.

\section{Keywords:}

Beach; Beach Profile; Topographic Survey; Emery Rods.

\section{Resumo:}

A realização de nivelamentos topográficos de perfis de praia tem se caracterizado pelo emprego crescente de equipamentos óticos/eletrônicos de custo de aquisição e manutenção cada vez maior em detrimento de métodos e equipamentos de baixo custo, na suposição de que tal escolha representa um aumento da acuidade dos dados. No presente trabalho é realizado uma comparação dos resultados do emprego do método das balizas de Emery, do nível topográfico, da Estação Total e do GNSSRTK (Global Navigation Satellite System). Os resultados encontrados indicam não haver diferenças significativas, independente de qual dos equipamentos for empregado, não se comprovando dessa forma, no caso da precisão requerida para perfis de praia, uma relação positiva entre a precisão do levantamento e seu custo.

\section{Abstract:}

The topographic leveling of beach profiles has been characterized by the increased use of optical and electronic equipment associated with an increase in the cost 
of acquisition and maintenance in detriment of low-cost equipment, in the supposition that this choice presents an increase of the acuity of the data. In the present work a comparison of the results of the use of the Emery's rod method compared to the topographic level, Total Station and GNSS-RTK (Global Navigation Satellite System) is performed. The results indicate that there were no significant differences independent which of the equipment was used, thus not proving, in the case of beach profiles, a positive relation between the accuracy of the survey and the cost of the equipment.

\section{Introdução}

Proposto em 1961 por Kenneth O. Emery, para a medição de perfis topográficos de praia, o método consiste no emprego de duas balizas, de $1,5 \mathrm{~m}$ de comprimento cada, em que a diferença de nível entre as mesmas é determinada empregando a linha do horizonte como referencial horizontal, com as distâncias, ao longo do perfil, sendo medidas utilizando o comprimento da própria baliza. Faixas de $2 \mathrm{~cm}$ de largura, em cores alternadas (vermelho e branco), pintadas em cada baliza, permitem ler a diferença de nível (Figura

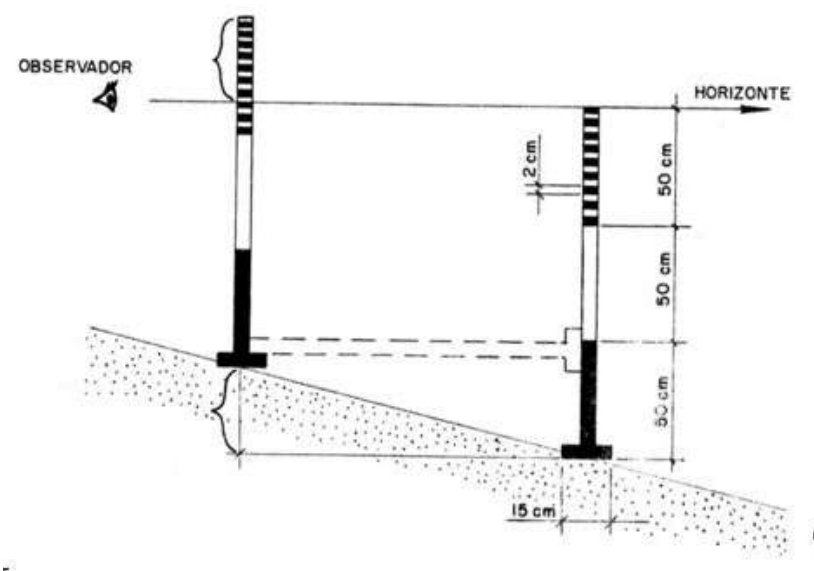

Figura 1 - À esquerda esquema do método das balizas de Emery (Fonte Kowsmann 1961), è direita foto do método em campo (Foto Dieter Muehe).

O método foi introduzido no Brasil pelo geólogo Renato Kowsmann ao realizar o monitoramento de um perfil na Praia de Copacabana (Kowmann, 1970). O método foi posteriormente amplamente empregado no país, passando, com o tempo a ser parcialmente substituído pelo nivelamento com teodolito ou, mais frequente, nível topográfico, e mais recentemente pelo emprego da Estação Total e mesmo do GPS diferencial (atualmente se usa de maneira mais recorrente a sigla GNSS referente a Global Navigation Satellite System que engloba diferentes constelações, como o GPS norte-americano, ou Glonass russo. Em relação ao RTK (Real Time Kinematics), este está ajustado à correção em tempo real das
1). O emprego de trena métrica para medição de distâncias permite acelerar o processo de medição assim como ajustar melhor os pontos de leitura às variações da topografia. A colagem de fita métrica em cada uma das balizas é outro ajuste que permite uma leitura mais rápida das diferenças de nível. Erros, tanto de altura quanto de distância, devido à tendência de inclinar as balizas no momento da leitura, podem ser minimizados com o emprego de um nível de bolha (nível de pedreiro). É um processo simples, suficientemente acurado considerando que numa praia arenosa a impressão de uma pegada já implica em variações centimétricas.

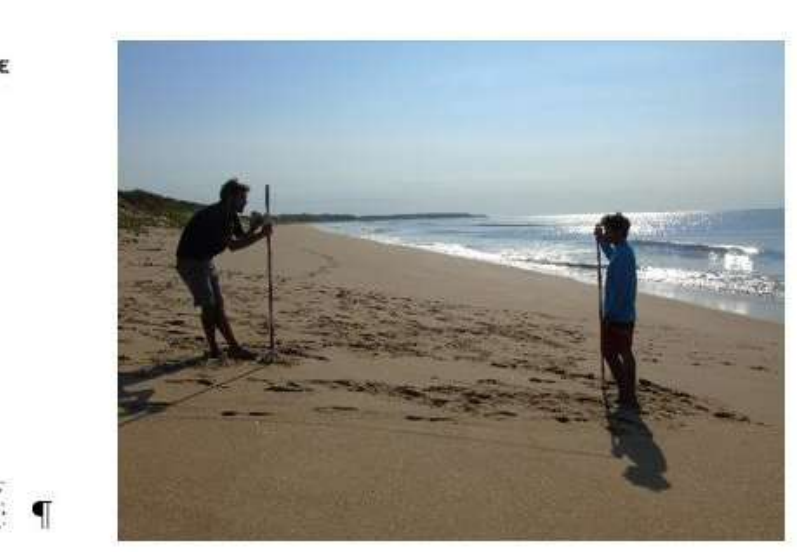


com ligeira defasagem na orientação a exigir correção no pós-processamento. Não obstante o interesse científico nesse tipo de avaliação, tratando-se de perfis de praia com a típica movimentação da superfície topográfica desta feição costeira por distúrbios devido ao pisoteio e casualmente por veículos e animais, sem considerar a mobilidade morfodinâmica devido à ondas e ventos, não parece ser a precisão a justificativa no emprego deste equipamento, principalmente considerando o diferencial de preço entre as diversas opções disponíveis (Figura 2). Naturalmente quando já há disponibilidade desses equipamentos devido a outras atividades de levantamento, o argumento de custo já não faz mais sentido, a não ser os custos decorrentes da manutenção e calibração dos mesmos, submetidos a um ambiente extremamente agressivo devido à proximidade do mar.

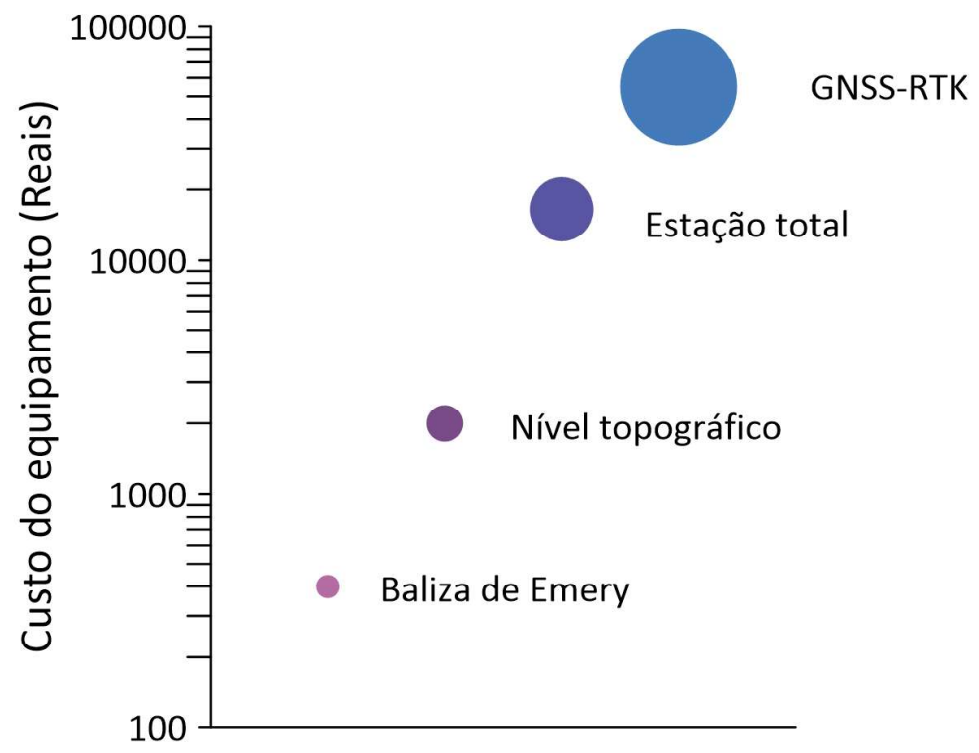

Figura 2 - Comparação da ordem de grandeza dos custos de equipamentos de nivelamento topográfico.

No presente estudo é feito uma comparação dos resultados obtidos com o emprego da baliza de Emery, do nível topográfico, da Estação Total e do GNSS-RTK (Figura 3).

\section{Metodologia}

Os levantamentos foram feitos ao longo de três perfis, localizados na Praia de Camburi, em Vitória - ES (Figura 4). Trata-se de uma praia de enseada, exposta na sua porção central às ondas de tempestade de sudeste e que, para conter o processo erosivo, foi segmentada por dois espigões. Em função da exposição a praia apresenta características morfodinâmicas diferenciadas, passando de dissipativa na extremidade sul, para refletiva na porção central e intermediária na porção norte, caracterizando-se a porção central por uma praia larga devido à retenção de sedimentos pelo espigão.

Para cada equipamento foi constituído um grupo independente. Num primeiro momento cada grupo efe- tuava o levantamento ao longo de cada perfil buscando, de forma independente, posicionar os pontos de medição de conformidade com as mudanças percebidas do relevo, buscando dessa forma reproduzir o modo usual desse tipo de levantamento. Em seguida, em data posterior, foi repetido o levantamento do perfil 1 , mas dessa vez com uma mesma equipe realizando o levantamento com cada um dos equipamentos, com os pontos de nivelamento pré-definidos e partindo de uma mesma cota, evitando assim os erros devidos à posição da maré.

Para fins de avaliação dos diferentes tempos de cada etapa do levantamento, foram anotados o tempo necessário para montar o equipamento, para realizar o levantamento e para o tempo gasto no pós-processamento. Cada um dos perfis foi levantado sem buscar uma competição no sentido de ver qual grupo consegue levantar mais rapidamente, mas sim, buscando manter as situações de levantamento como ocorre na prática. Dependendo da habilidade e experiência de cada operador e equipe, resultados ligeiramente diferentes podem ser encontrados. 


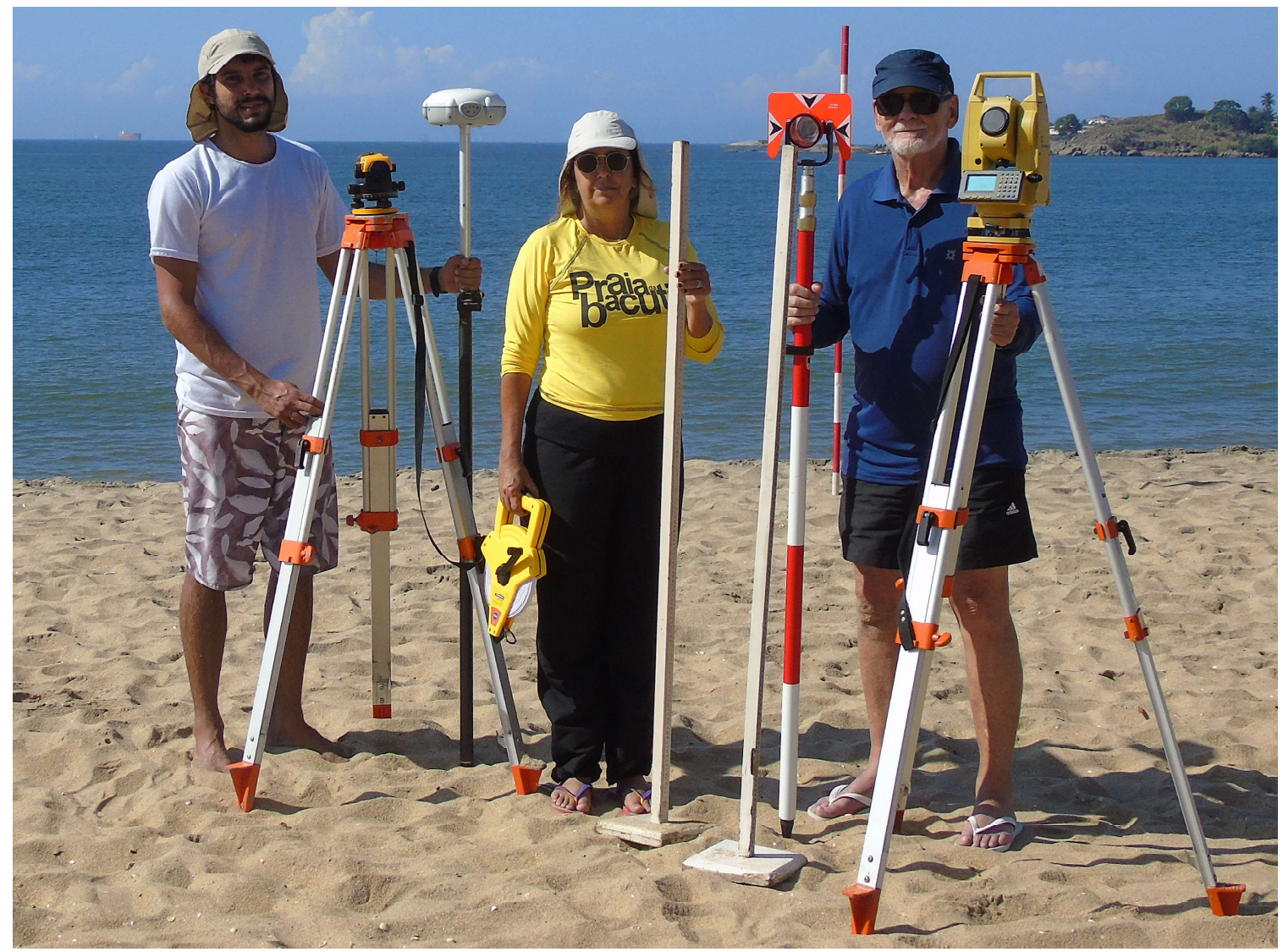

Figura 3 - Equipamentos empregados, da esquerda para a direita: nível topográfico, GNSS-RTK, balizas de Emery, Estação Total.

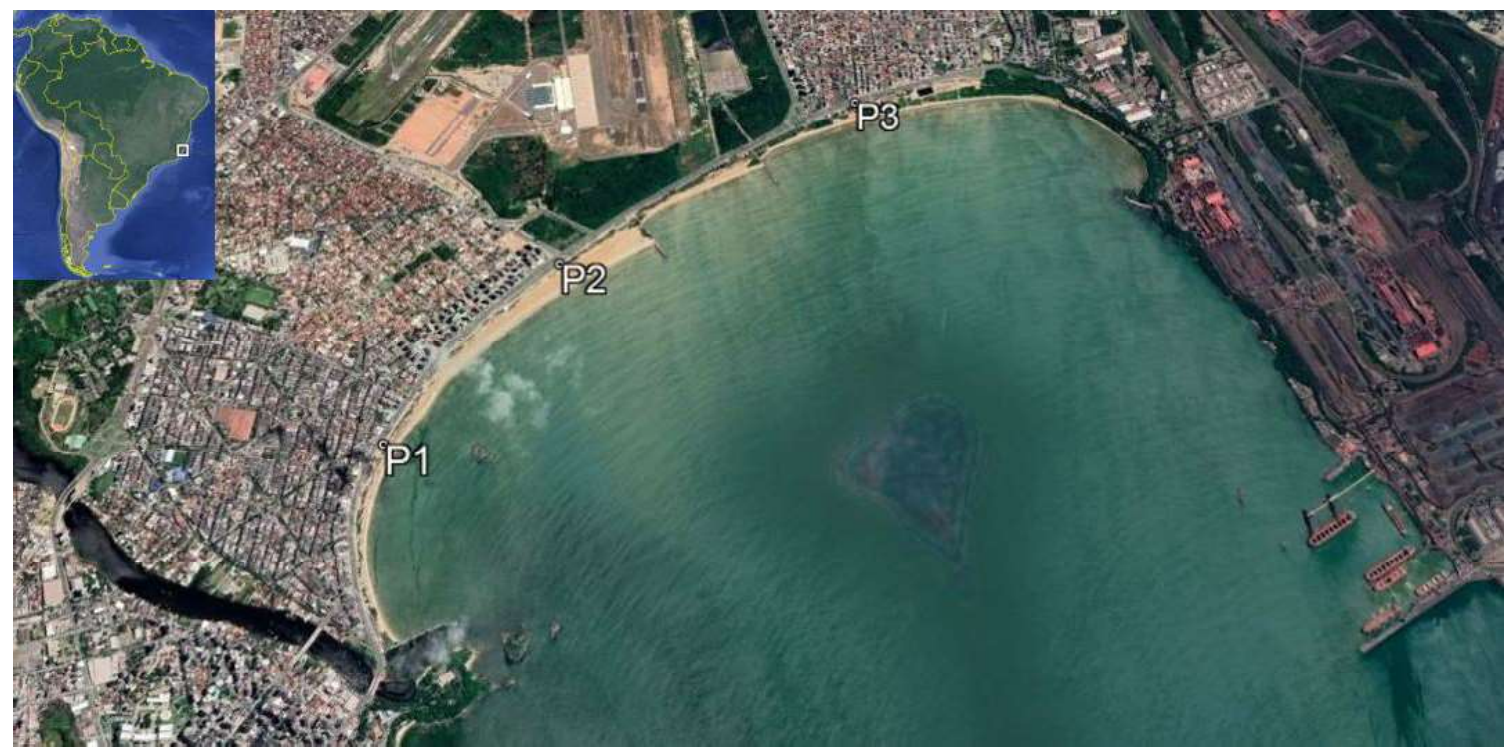

Figura 4 - Praia de Camburi em Vitória - ES, com localização dos perfis de nivelamento topográfico

O datum vertical para cada perfil foi ajustado ao nível do mar na posição do refluxo da onda e posteriormente corrigido para o nível médio previsto para o Porto de Tubarão, em Vitória, localizado nas proximi- dades imediatas da área de levantamento, utilizando o método proposto por Bigarella et al. (1961) e Muehe (2003). No caso do GNSS-RTK também foi utilizado esse método de ajuste vertical em vez da obtenção da 
altitude ortométrica, devido à falta de um ponto de rastreamento de longo prazo.

Na plotagem dos dados do nivelamento, normalmente fornecidos em termos de distância e cota, os do
GNSS-RTK, por virem em coordenadas geográficas, foram transformados em distâncias acumuladas empregando a planilha originalmente prevista para a correção de desvio de rumo de perfis batimétricos (Muehe, 2004, 2006).

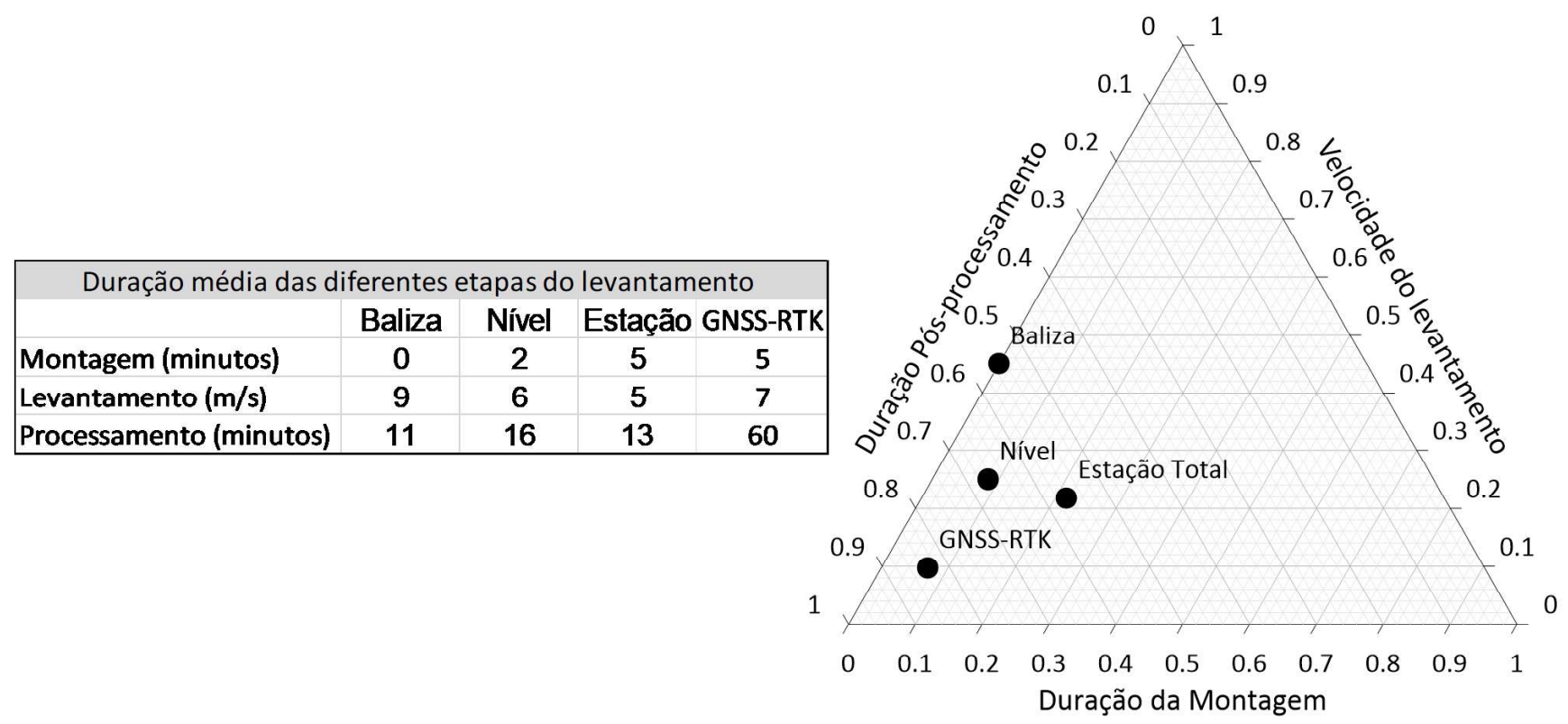

Figura 5 - À esquerda a duração média das diferentes atividades de levantamento no conjunto de perfis e à direita diagrama ternário das posições relativas entre si destas atividades.

\section{Resultados}

A plotagem, em diagrama ternário, dos tempos médios gastos em cada passo do levantamento, mostrou que a Estação Total demandou o maior tempo para a montagem, enquanto que no emprego das balizas o tempo foi nulo já que a mesma pode ser empregada sem nenhum preparo anterior. A velocidade de levantamento foi a maior na Baliza de Emery e menor na Estação Total (Figura 5). Já a duração do pós-processamento, isto é a preparação das planilhas e desenho dos perfis, foi o menor na Baliza de Emery e maior no GNSS-RTK.

A superposição dos perfis levantados com emprego dos diferentes equipamentos mostrou coerência entre os resultados obtidos, com pequenas diferenças de altitude resultantes da posição do refluxo da onda considerado por cada equipe. Essas diferenças foram corrigidas ao adotar um mesmo datum vertical igual para cada perfil (Figura 6). Outras diferenças resultaram de diferenças nos espaçamentos dos pontos de nivela- mento, da posição horizontal do refluxo das ondas, o que resultou no espraiamento da face da praia em alguns dos perfis e de erros de leitura.

Considerando que o objetivo principal do trabalho foi o de comparar os perfis levantados com balizas em relação a outros equipamentos, verifica-se que os perfis levantados com baliza se situaram sempre no interior do envoltório do conjunto de perfis e nos perfis 1 e 2 , muito próximos dos perfis do GNSS-RTK.

Na Figura 7 é apresentado o resultado do levantamento controlado em termos de datum vertical e espaçamento dos pontos de nivelamento. No caso do GNSS-RTK o resultado variou em torno do perfil para cima e para baixo em ordem de grandeza de decímetros a quase 1 metro. Possíveis problemas associados à degradação do sinal pela ionosfera e troposfera e pela quantidade e geometria da constelação de satélites podem influenciar na degradação do sinal no momento do levantamento (BARBOSA., et al 2010). 

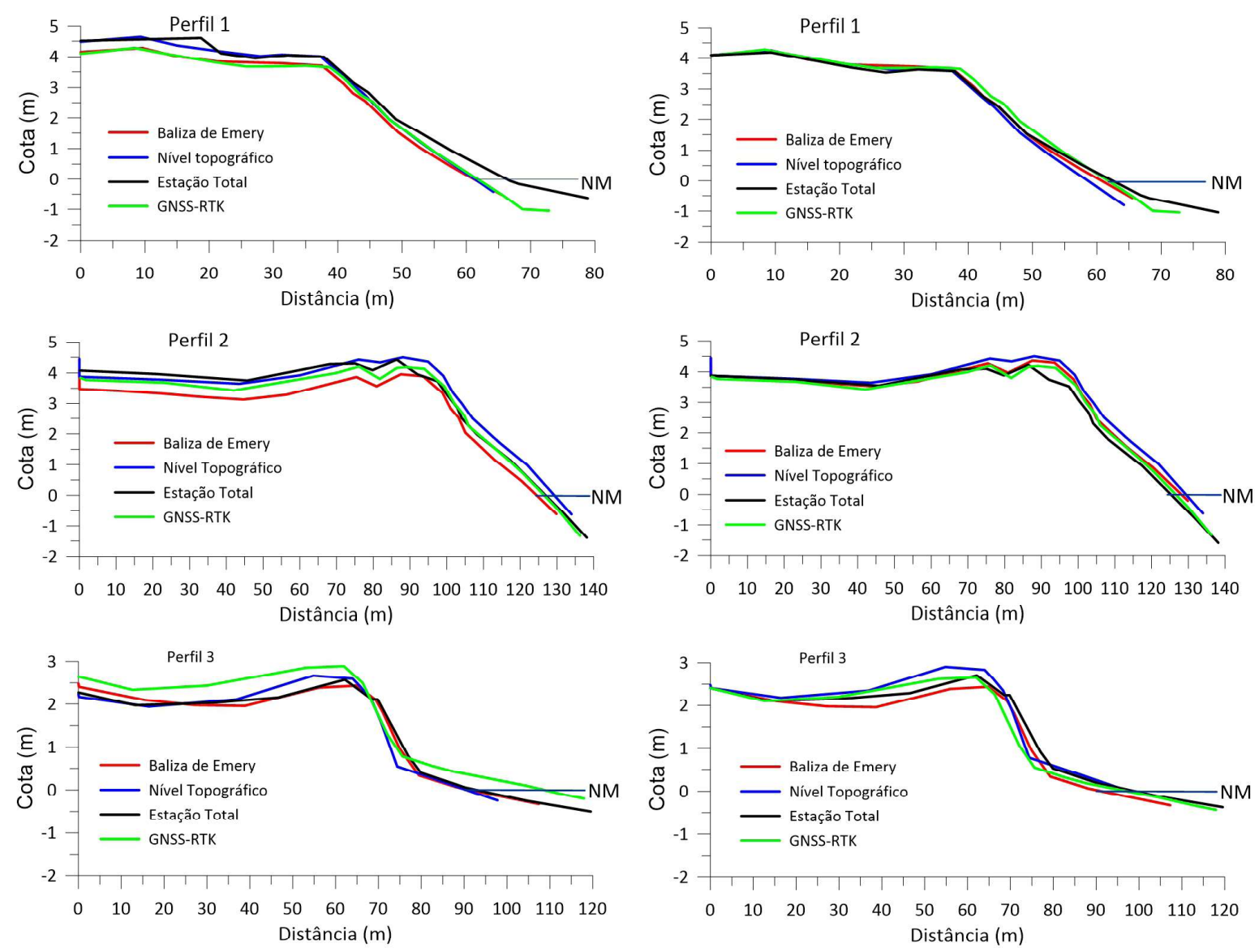

Figura 6 - Superposição dos perfis levantados em cada perfil. À esquerda sem ajuste vertical è à direita com ajuste.

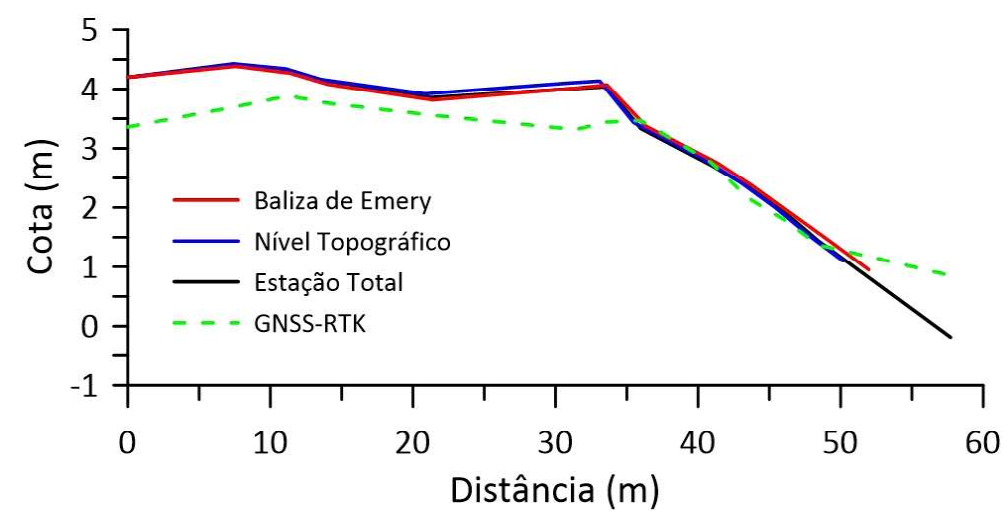

Figura 7 - Superposição dos perfis levantados a partir de um mesmo datum vertical e mesmos pontos de medição.

\section{Considerações finais}

A comparação de perfis levantados com as balizas de Emery com os levantados com outros equipamentos mostrou que os resultados são idênticos e adequados dentro das exigências de um monitoramento de perfis de praia. Assim sendo a escolha do método é mais uma questão de custo ou de disponibilidade de equipamentos mais sofisticados, sem que isto resulte em aumento de precisão. Equipamentos sofisticados como a Estação Total e o GNSS-RTK porém apresentam vantagens quando os levantamentos incluem áreas sem visibilidade do horizonte, como no levantamento da morfologia de campo de dunas por exemplo que, no caso do GNSS-RTK pode ser levantado com apenas um operador ou dois operadores no caso da Estação Total. Restrições de uso resultam de efeitos meteorológicos 
adversos, como chuva, cobertura de nuvens, presença de árvores e proximidade de falésias, que degradam o sinal do satélite. Quanto às balizas de Emery há restrição quando se quer estender o perfil para a zona de surfe e antepraia. Com ondas baixas é possível adentrar pequena distância da zona de surfe mas, assim que as ondas impedem a visão do horizonte ou que a profundidade se torna maior que o comprimento das balizas, não é possível avançar. Essa restrição também se aplica, se bem que em menor escala, à Estação Total e ao GNSS-RTK pois, tanto o prisma da Estação quanto a antena do GNSS-RTK, precisam ser protegidos sendo que o portador destes equipamentos tem enorme dificuldade em se manter estável sob condições de ondulação, ficando ainda a profundidade a ser sondada também limitada à altura da baliza de suporte do prisma ou da antena. Ainda no caso da Estação Total é extremamente difícil realizar a medição devido à instabilidade da posição do prisma. Para esses casos a melhor alternativa é o emprego do nível topográfico ou do teodolito podendo-se atingir profundidades apenas limitadas pelo comprimento da mira topográfica, ou ainda com o emprego de um trenó submarino como suporte à mira topográfica ou prisma (Muehe e Silva, 1996; Martins et al, 1998).

Em suma, os dados mostram que o emprego do método das balizas, quando restrito ao levantamento de perfis de praia, apresenta, em termos práticos, o mesmo grau de precisão de equipamentos sofisticados, sendo seu emprego totalmente satisfatório considerando a precisão requerida para o tipo de levantamento em questão. Pode não ser a opção individual preferencial quando da disponibilidade de outros equipamentos, mas para estudantes sem maiores recursos ou para aulas práticas em todos os níveis de ensino e mesmo num monitoramento profissional, é um método que permite realizar o levantamento sem elevados custos de aquisição. Até mesmo no ensino básico, uma aula de geografia física com trabalho de campo, permitiria aos alunos acompanhar a variabilidade da morfologia de uma praia, estabelecer associações como o clima de ondas, perceber o que é vulnerabilidade costeira, enfim torna-los cidadãos mais motivados para compreender os processos físicos da zona costeira e os riscos associados às mudanças globais.

\section{Referências Bibliográficas}

BARBOSA, E.M.; MONICO, J.F.G.; ALVES. D.B. M.; OLIVEIRA, L.C. Integridade no posicionamento RTK e RTK em rede. Boletim de Ciências Geodésicas, Curitiba, v. 16, n. 4, p.589-605, 2010.

BIGARELLA, J.J.; SALAMUNI, R.; MARQUES F.P.L. Método para avaliação do nível oceânico à época da formação dos terraços de construção marinha. Boletim Paranaense de Geografia, v.4/5, 1961 .

EMERY, K.O. A simple method of measuring beach profiles. Limnological Oceanography, v.6, p. 90-93, 1961. Disponível em: https://doi.org/10.4319/lo.1961.6.1.0090

HUANG, JD.; JACKSON, D.W.T.; COOPER, J.A.G. Morphological monitoring of a high energy beach system using GPS and Total Station techniques. Journal of Coastal Research, SI 36, p. 390-398, 2002. https://www.jcronline.org/ doi/pdf/10.2112/1551-5036-36.sp1.390.

MARTINS, R.R.; TOLDO JR., E.E.; ALMEIDA, L.E.S.B. Trenó para medidas do fundo da zona de surfe. Revista Brasileira de Recursos Hídricos, Porto Alegre, RS, v.3, n.1, p. 105-110, 1998. DOI: $10.21168 /$ rbrh.v3n1.p105-110

MUEHE, D.; ROSO, R.; SAVI, D. C. Avaliação de método expedito de determinação do nível do mar como datum vertical para amarração de perfis de praia. Revista Brasileira de Geomorfologia, Goiânia, v. 4, n.1, p. 53-57, 2003. DOI: http:// dx.doi.org/10.20502/rbg.v4i1.19.

MUEHE, D.. Método de levantamento topo-batimétrico do sistema praia-antepraia. Revista Brasileira de Geomorfologia, Uberlandia, v. 5, n.1, p. 95-100, 2004. DOI: http://dx.doi. org/10.20502/rbg.v4i1.19

MUEHE, D. Método de levantamento topo-batimétrico do sistema praia-antepraia. Errata. Revista Brasileira de Geomorfologia, Uberlandia, v. 7, n.1, 2006. Disponível em: <http://www.lsie. unb.br/rbg/index.php/rbg/article/view/283/203>

MUEHE, D.; SOUZA, S.R. Determinação do perfil de praia na zona de surfe e arrebentação através do emprego do trenó submarino. Notas Téenicas, Univ.Fed.Rio Grande do Sul, v. 10, p. 1-5, 1996. KOWSMANN, R. Variações de curto e longo prazo de um perfil da praia de Copacabana, Rio de Janeiro. Publicação do Instituto de Pesquisas da Marinha, Rio de Janeiro, v. 39, 16p., 1970. 